\title{
It's Not Only Size That Matters: Trust and E-Government Success in Europe
}

\author{
Fabian Stephany \\ Oxford Internet Institute, University of Oxford, \\ Humboldt Institute for Internet and Society, Berlin \\ fabian.stephany@oii.ox.ac.uk, ORCID ID 0000-0002-0713-6010
}

\begin{abstract}
User data fuel the digital economy, while individual privacy is at stake. Governments react differently to this challenge. Estonia, a small Baltic state, has become a role model for the renewal of the social contract in times of big data. While e-governance usage has been growing in many parts of Europe during the last ten years, some regions are lagging behind. The Estonian example suggests that online governance is most accepted in a small state, with a young population, trustworthy institutions and the need of technological renewal. This work examines the development of e-governance usage (citizens interacting digitally with the government) during the last decade in Europe from a comprehensive cross-country perspective: Size, age and trust are relevant for the usage of digital government services in Europe. However, the quality of past communication infrastructure is not related to e-governance popularity.
\end{abstract}

Keywords: E-Governance, Europe, Estonia, Random Model, Trust.

This is a pre-print version of an article forthcoming as: Stephany, F. (2020) "It's not only size that matters: determinants of Estonias egovernance success", Electronic Government, Vol. 16, No. 3, pp.304-313, DOI: $10.1504 /$ EG.2020.10028669

\section{Introduction}

Personal data have become a valuable resource. In fact, many digital applications and business solutions in the digital economy would not be imaginable without the constant flow of user data. Users have become "spinning wheels of data" 1 . The question of data protection has become immanent. Data-leaks, such as the scandal about the exploitation of Facebook data by the research firm Cambridge Analytica, question the security of our personal data. How to protect individual privacy, while not hindering the free flow of data in the digital economy? Governments have reacted differently to this challenge, with questionable outcomes for democracy and individual freedoms. China is explicitly making use of citizens' personal data for the surveillance and control of its society. In the

\footnotetext{
${ }^{1}$ To put it with the words of tech-author Andrew Keen 1.
} 
US, private sector companies are the largest owners of citizen data. In contrast, Estonia, a Baltic state with roughly 1.5 million inhabitants, delivers a positive role model for the renewal of the social contract in times of big data. The Estonian model relies on transparency and accountability: Most user data are openly available to government institutions, while citizens can follow up every single request of their data and have the right to demand clear justifications for its usage.
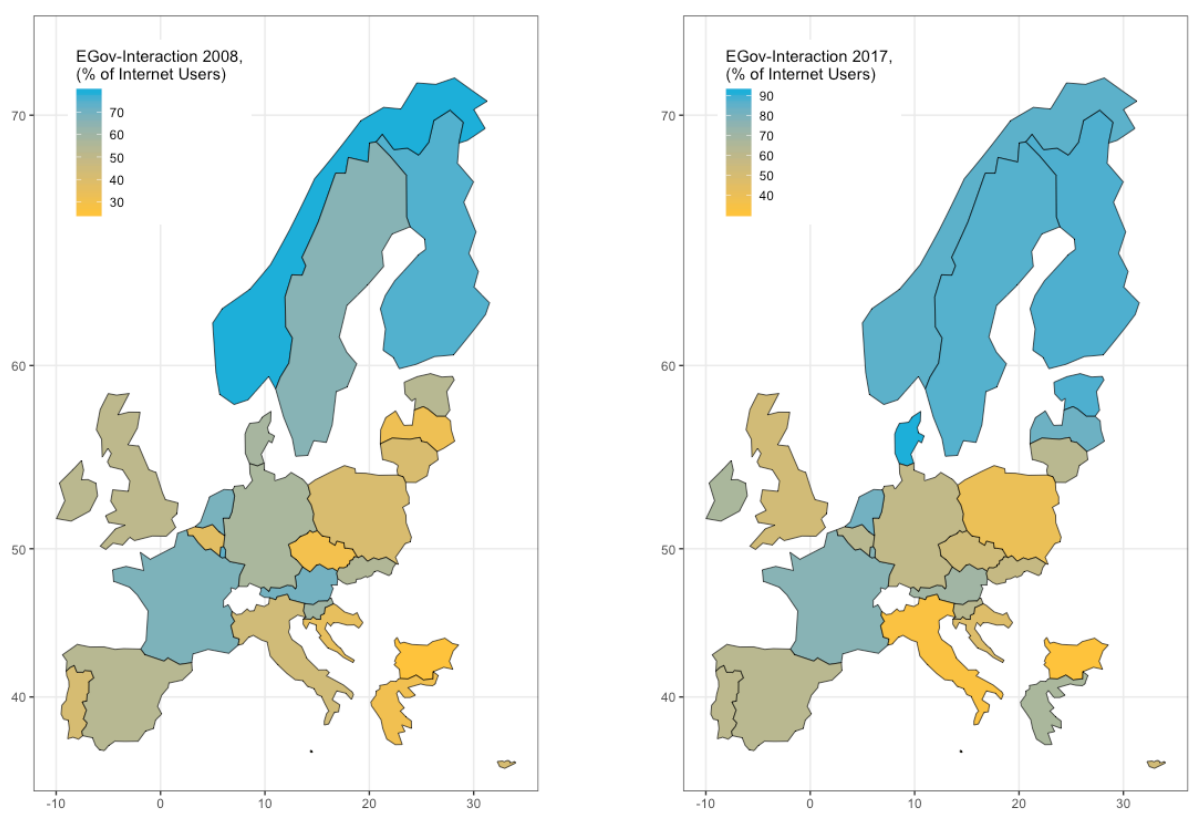

Fig. 1. In the EU, online interaction with between citizens and their governments has been staidly rising over the past ten years. In Estonia and its Scandinavian neighbours, almost all internet users regularly exchange information with their government online.

The Estonian model works well. Every citizen owns a digital identity and electronic signature. Via the country's decentralised data highway all public request: $2^{2}$ can be efficiently and securely processed with minimal administrative burden for citizens and civil servants. Estonia is not the only country in Europe where digital governance solutions are exemplary. As shown in figure1, in 2017, nine out of ten internet users from Estonia regularly exchange information with the government online. The same is true in countries like Norway, Sweden or Denmark. Overall, e-governance usage has been growing in most of Europe during the last ten years. However, in countries like Italy, Bulgaria or Poland, more

\footnotetext{
${ }^{2}$ Marriage, divorce, and property selling still require physical presence.
} 
than half of the internet users are not engaged in e-governance. How unique is the Estonian tale of digital modernisation? This work empirically examines e-governance usage on a European cross-country perspective from 2008 to 2017. The unit of observation is the national share of internet users that have interacted digitally with their government at least once in the last three months. The example of the Estonian role model suggests that online governance is most successful in (1) small countries with (2) a young population, (3) high trust in institutions, and (4) a need for technological renewal. The research question of this work is if the success determinants of the Estonian example can be generalised in other countries, too. Mostly, the success of Estonia's e-governance is assigned to the historical change the country had after the fall of the iron curtain. In order to ensure data harmonisation and a minimum level of socio-economic comparability, the analysis focuses on EU countries. This analysis finds references that size, age, and confidence in legal institutions are indeed related with the development of electronic governance. However, the argument of technological leapfrogging 3 , often suggested in the case of Estonia, can not be confirmed.

\section{Literature}

The story of Estonia's e-governance is celebrated worldwide as an example for the digital renewal of the social contract. Policy makers and digital entrepreneurs look jealously at the small Baltic and often explain the country's high quality and acceptance of e-services with its unique historical starting point. The argument of technological leapfrogging is very prominent: After the collapse of the Soviet Union, Estonia, was left without a functioning system of communication infrastructure. As Toomas Hendrik Ilves, the former Estonian president and key figure in the post-soviet modernisation, had put it: "In 1993, Estonia had the telephone system of 1938" [2]. With little previous communication infrastructure in place, countries like the early independent Estonia have the chance and need for a fresh start [3. However, the literature knows at least three other prerequisites for high acceptance rates of e-governance. First, size is said to be of advantage. The initial physical registration of citizens with the digital system and their subsequent training explain advantages of smaller countries [4/5]. Secondly, the demographic structure of the population plays an important role. The larger the share of digital natives 4 , the less time and effort is required to convince citizens about the effectiveness and security of digital solutions [5]6. Thirdly, successful digital (government) services demand trust $7 / 8 / 9|10| 11$. In fact, this aspect is quite visible for the Estonia case. The entire Estonian e-governance infrastructure is constructed around the idea that citizens trust their institutions. The

\footnotetext{
3 The concept of leapfrogging is being used in the context of sustainable development as a theory of development which may accelerate development by skipping inferior, less efficient, more expensive or more polluting technologies and industries and move directly to more advanced ones.

${ }^{4}$ The term here refers to individuals that grew up with the daily usage of digital technologies like the internet.
} 
credibility of digital certificates 5 or the enforcement of legal consequences in the case of data abus $\oint^{6}$ require institutional credibility [12.

In sum, the success of Estonia's e-governance is very often explained with the country's small population size and the nation's unique starting settings after the collapse of the Soviet Union. However, several other smaller countries in Europe had similar, supposedly favourable, initial conditions for building a successful e-governance infrastructure. The scope of the following analysis is to highlight the particular features that might explain high e-governance participation rates in Europe with the blueprint of the Estonian success story. The analysis examines, if the most important, features of the Estonian e-governance success are of systematic importance for high e-governance usage in Europe.

\section{Data}

The investigation makes use of three different data sources. First, measures about the usage of digital services (egov), as well as the information about population siz $7^{7}(p o p)$, and demographic structure ${ }^{8}(a g e)$ is derived from the Eurostat database. The value of egov refers to the share of internet users that have interacted digitally with the government at least once in the last three month: 9 The prerequisites for this measure are two-fold. First, governments must provide the necessary infrastructure and citizens need to be willing to engage with it. Secondly, the European Social Survey, supplies a measure of trust in institutions (trstlgl) $)^{10}$ Lastly, the Worldbank database yields information about the development of the last generation telecommunications infrastructure, which is measure with the number of fixed telephone lines per 100 inhabitants $(t l p h)$. In addition, the variable svt indicates if the country had been a part of the Soviet Union 11 The final dataset contains 288 observations. It includes 27 countries and covers the years 2008 to $2017^{12}$.

\footnotetext{
${ }^{5}$ Digital certificates link legal entities and individuals with their online authentication method, such as their private keys in a Public-Key-Infrastructure.

6 The approvals of doctors and lawyers, who overstepped their data access rights, has been withdrawn in several cases in Estonia.

7 In logarithmic values.

8 The age dependency ratio: the number of individuals older than 65 years, divided by the number of individuals between 15 and 65 years of age

9 Similarly, Eurostat tracks the number of internet users that have a) visited a governmental page, b) downloaded documents from, or c) uploaded files to a web-page of their government. Of all three e-governance measures, egov correlated strongly with the remaining three indicators.

10 The survey question reads: "...please tell me on a score of 0-10 how much you personally trust the legal system in your country. 0 means you do not trust the institution at all, and 10 means you have complete trust."

${ }^{11}$ Both former members and satellite states are included.

${ }^{12}$ Where possible, missing values of trstlgl and tlph are imputed with the values of the previous or following year.
} 


\section{Results}

First, the four potential drivers of e-governance usage, size, age, trust, and technological leapfrogging are examined in a sample of countries with the lowest and highest e-governance rates in 2017. One possible explanation for the success of the Estonian model is population size. The digital transformation of public services is easier in smaller countries. The data supports this line of reasoning. In 2017, the five countries with the highest rates of e-governance interaction contribute to five percent of the sample's population ${ }^{13}$, while the five countries with the lowest interaction rates make up 35 percent of the sample Similarly, it is said that e-governance services are easier to establish in relatively young societies. However, the top-bottom comparison shows a different picture. The age-dependency ratio in the five top performing countries (55.70) is three percent points higher than in the bottom five (52.60). Trust in institutions is outlined as a third prerequisite for successful e-governance. The top-bottom comparison strengthens this claim. In 2017, individuals from top performing countries report significantly higher levels of trust $(6,24)$ in their legal institutions than citizens of the bottom five $(4,87)$. Lastly, it is assumed that countries with a weak communication infrastructure in the past face a greater pressure for adopting digital governance. Estonia, which was left with a dysfunctional communication infrastructure after Soviet times, is a good example for this case. However, this case can not be generalised. The count of fixed telephone lines per 100 inhabitants is the same for bottom (33 percent) and top (30 percent) countries. At the same time, three of the low performing countries have been under Soviet influence, while Estonia is the only post-soviet country among the top five.

After this first impression, a more comprehensive analysis of the sample follows. Figure 2 summaries the relationship between the key variables of interest in all 27 countries from 2008 to 2017. Three countries with low (Poland), middle (the UK), and high levels (Finland) of e-governance interaction are highlighted. In quadrant $\mathrm{A}$, a general positive tendency between age and e-governance interaction is visible. For most countries, like the UK and Poland, the level of egov remains constant over time. Quadrant B shows a clearly positive relationship between citizens' trust in legal institutions and e-governance interaction. This pattern is time invariant for almost all countries. In quadrant $\mathrm{C}$, we find no clear overall relationship between last generation's telecommunication and e-governance. However, for some countries, like Finland and Poland, this relationship is negative over time. Lastly, quadrant $\mathrm{D}$ shows the comparison of e-governance between countries with and without a Soviet past. In fact, interaction rates are rather high in countries that have not been under Soviet influence.

The empirical analysis is completed by a regression models in table 1 . The dependent variable is egov, while pop, age, tlph, and trstlgl are selected as independent variables. The comparison in figure 2 shows that some of the dependent

\footnotetext{
${ }_{13}$ Denmark (92\%), Estonia (88\%), Finland (88\%), Iceland (87\%), and Sweden (87\%) had a total 2017 population of 22.901 .203 .

${ }^{14}$ Bulgaria (31\%), Italy (33\%), Poland (40\%), Croatia (47\%), and the UK $(52 \%)$ had a total 2017 population of 176.481.856.
} 
Fabian Stephany

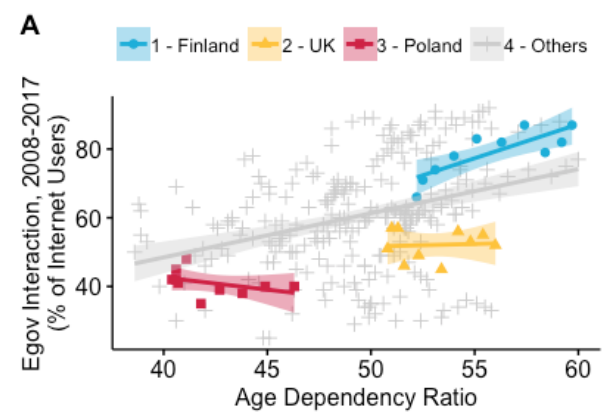

B

$\rightarrow 1$ - Finland $\rightarrow 2$ - UK $=-3$ - Poland -4 - Others
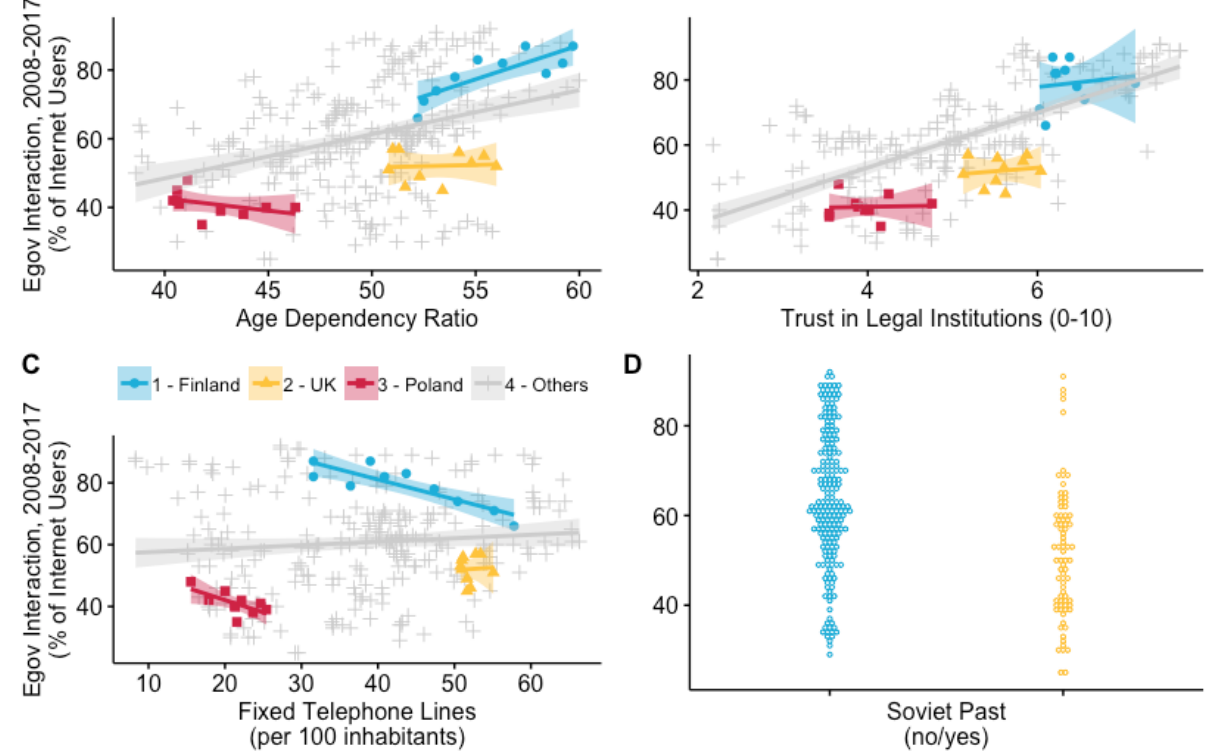

Fig. 2. Age (quadrant A) and trust (quadrant B) are positively associated with egovernance interaction. In the case of age, this relationship varies over time and across entities.

Table 1. Explanations for usage of e-governance services in Europe (2008-2017): Interaction is higher in less populous countries, with an older population, and more trust in institutions.

\begin{tabular}{|c|c|c|c|c|c|c|}
\hline & \multicolumn{6}{|c|}{ Dependent variable: } \\
\hline & \multicolumn{6}{|c|}{ E-Governance Interaction - Random Models } \\
\hline & $(1)$ & $(2)$ & (3) & $(4)$ & $(5)$ & (6) \\
\hline pop & $\begin{array}{c}-2.465 \\
(2.148)\end{array}$ & & & & $\begin{array}{c}-3.765^{* * *} \\
(1.419)\end{array}$ & $\begin{array}{c}-4.112^{* * *} \\
(1.369)\end{array}$ \\
\hline age & & $\begin{array}{l}1.609^{* * * *} \\
(0.199)\end{array}$ & & & $\begin{array}{l}1.376^{* * *} \\
(0.224)\end{array}$ & $\begin{array}{l}1.502^{* * *} \\
(0.208)\end{array}$ \\
\hline tlph & & & $\begin{array}{c}-0.475^{* * *} \\
(0.096)\end{array}$ & & $\begin{array}{c}-0.143 \\
(0.091)\end{array}$ & \\
\hline trstlgl & & & & $\begin{array}{l}5.154^{* * *} \\
(0.969)\end{array}$ & $\begin{array}{l}2.883^{* * *} \\
(0.944)\end{array}$ & $\begin{array}{l}2.754^{* * *} \\
(0.932)\end{array}$ \\
\hline Constant & $\begin{array}{l}98.545^{* * *} \\
(34.312)\end{array}$ & $\begin{array}{c}-20.628^{* *} \\
(10.216)\end{array}$ & $\begin{array}{l}77.288^{* * *} \\
(4.708)\end{array}$ & $\begin{array}{l}33.988^{* * *} \\
(5.154)\end{array}$ & $\begin{array}{r}42.160^{*} \\
(23.447) \\
\end{array}$ & $\begin{array}{c}36.610 \\
(22.735) \\
\end{array}$ \\
\hline Observations & 226 & 226 & 226 & 226 & 226 & 226 \\
\hline & 0.011 & 0.218 & 0.093 & 0.096 & 0.276 & 0.271 \\
\hline Adjusted $\mathrm{R}^{2}$ & 0.006 & 0.215 & 0.089 & 0.092 & 0.263 & 0.261 \\
\hline
\end{tabular}


variables have no impact on e-governance interaction over time, while in some countries a within-country relationship is visible. Therefore a random effects model is selected [13]: $y_{i t}=X_{i t} \beta+u_{i t}$. For every country $(i)$ and year $(t)$, the governance usage rate $\left(y_{i t}\right)$ is explained by the set of dependent variables $\left(X_{i t} \beta\right)$.

The results of the random effects model confirm most of the observations made after the top-bottom comparison. Population size, in the full model (5), is negatively related to egov. Interestingly for age, we see a positive relationship with e-governance usage. This contradicts the widely held assumption about the advancement of digital governance in younger societies. As expected, trust in legal institutions shows a strong and positive association with egov. The degree of previous communication infrastructure, measured in fixed telephone lines per 100 capita, is not statistically related to e-governance usage, in the full model.

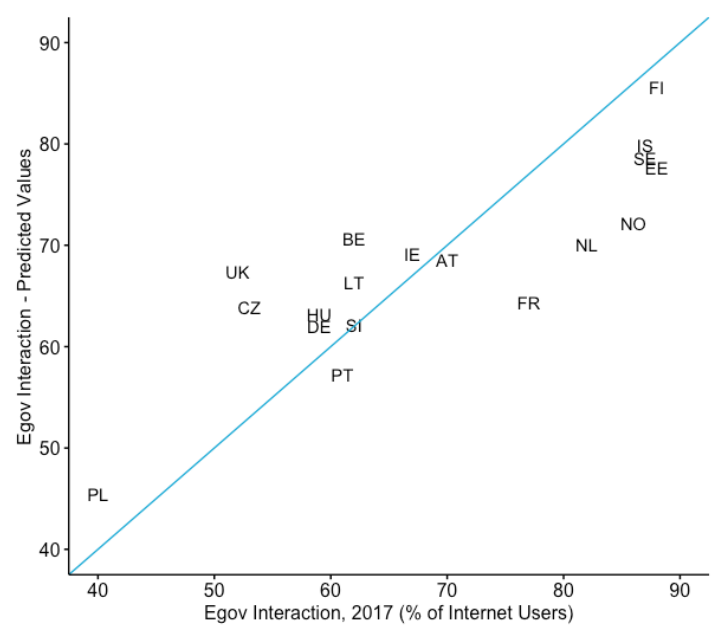

Fig. 3. For the year 2017, predicted and actual e-governance interaction rates are compared. The cross-validation slightly underestimates high values and overestimates low rates.

As an additional check for the validity of model (6), including pop, age, and trstlgl, a cross-validation is performed. With a truncated sample, containing the years 2008 to 2016, the values of egov for the sample's last year are estimated. The relationship between actual and fitted values for 2017 is shown in figure 3 . The in-sample estimation works well, on average. The values for countries at the lower end of the spectrum are slightly overestimated, while the opposite is the case for countries with high levels of e-governance interaction. 


\section{Conclusion}

Countries like Estonia, have become the role models for the digital renewal of the social contract. The Estonian example suggests that e-governance is most accepted in small countries, overcoming dysfunctional past communication infrastructure, with a young population that shares high trust in institutions. At least the first two aspects are frequently mentioned in the form of anecdotal evidence, but rarely tested empirically, on a macro-level. Here, the validity of the four drivers of digital modernisation is analysed in a sample of 27 European countries between 2008 and 2017. As for population size, the investigation confirms that e-governance usage is higher in small countries. For age, however, the Estonian case is contested. E-governance usage rates are higher in older societies. Clearly, the argument of trust is supported by the empirical evidence. Where citizens have high levels of trust in their legal institutions, e-governance interaction is high. Lastly, the results do not support the argument of leapfrogging. Previous generation's communication infrastructure is not related to e-governance interaction rates. Likewise, post-soviet countries on average have no advantage in adapting digital governance. The Estonian success story of digital modernisation does clearly not apply universally in Europe.

This work should serve as a starting point for future in-depth investigations. In particular, for countries in which the gap between predicted and actual e-governance usage is largest (Figure 3), case studies could deliver valuable findings that explain divergence. Two particularly interesting cases would be Latvia and Lithuania that share Estonia's strategic advantage of size and history condition, but are not as successful with regard to e-governance usage as their eastern Baltic neighbour. 


\section{Appendix}

Table 2. With the exception of trust in legal institutions trstlgl, observations are available for all 27 countries and nine years.

\begin{tabular}{lccccccc}
\hline \hline Statistic & N & Mean & St. Dev. & Min & Pctl(25) & Pctl(75) & Max \\
\hline egov & 288 & 60.396 & 15.908 & 25 & 49 & 71 & 92 \\
pop & 288 & 15.733 & 1.475 & 12.662 & 14.902 & 16.236 & 18.229 \\
age & 288 & 49.648 & 4.413 & 38.600 & 46.875 & 52.425 & 60.000 \\
tlph & 288 & 38.371 & 13.314 & 8.310 & 28.141 & 47.779 & 66.324 \\
svt & 288 & 0.278 & 0.449 & 0 & 0 & 1 & 1 \\
trstlgl & 226 & 5.014 & 1.272 & 2.176 & 4.018 & 5.866 & 7.679 \\
\hline
\end{tabular}

Table 3. The final sample, with full availability of all variables, includes 27 countries.

\begin{tabular}{lccc}
\hline \hline Country & ISO 2 & N & Years \\
\hline Austria & AT & 5 & $2013-2017$ \\
Belgium & BE & 9 & $2008-2017$ \\
Bulgaria & BG & 6 & $2008-2014$ \\
Cyprus & CY & 6 & $2008-2014$ \\
Czech Republic & CZ & 9 & $2008-2017$ \\
Germany & DE & 9 & $2008-2017$ \\
Denmark & DK & 8 & $2008-2016$ \\
Estonia & EE & 8 & $2009-2017$ \\
Greece & EL & 4 & $2008-2012$ \\
Spain & ES & 9 & $2008-2017$ \\
Finland & FI & 9 & $2008-2017$ \\
France & FR & 9 & $2008-2017$ \\
Croatia & HR & 4 & $2008-2012$ \\
Hungary & HU & 9 & $2008-2017$ \\
Ireland & IE & 9 & $2008-2017$ \\
Iceland & IS & 5 & $2011-2016,2017$ \\
Italy & IT & 5 & $2012-2014,2016,2017$ \\
Lithuania & LT & 7 & $2010-2017$ \\
Latvia & LV & 3 & $2008-2010$ \\
Netherlands & NL & 9 & $2008-2017$ \\
Norway & NO & 9 & $2008-2017$ \\
Poland & PL & 9 & $2008-2017$ \\
Portugal & PT & 9 & $2008-2017$ \\
Sweden & SE & 9 & $2008-2017$ \\
Slovenia & SI & 9 & $2008-2017$ \\
Slovakia & SK & 6 & $2008-2014$ \\
United Kingdom & UK & 9 & $2008-2017$ \\
\hline & & & \\
& & &
\end{tabular}




\section{References}

1. A. Keen, E-stonia: the country using tech to rebrand itself as the anti-russia (2016). URL E-stonia:thecountryusingtechtorebranditselfastheanti-Russia

2. K. Hjelmgaard, From jersey to estonia, a president pushes technology (2013). URL $\quad$ https://eu.usatoday.com/story/news/world/2013/12/23/ estonia-president-toomas-hendrik-ilves/3877149/

3. S. Haque, P. Pathrannarakul, E-government towards good governance: A global appraisal, Journal of E-governance 36 (1) (2013) 25-34.

4. C.-M. Teiu, An overview over the worldwide development of e-government.

5. H. Margetts, A. Naumann, Government as a platform: What can estonia show the world (2017) 1-41.

6. M. M. Nielsen, egovernance and online service delivery in estonia, in: Proceedings of the 18th Annual International Conference on Digital Government Research, ACM, 2017, pp. 300-309.

7. F. Stephany, F. Braesemann, M. Graham, Coding together-coding alone: The role of trust in collaborative programming.

8. F. Stephany, It deepens like a coastal shelf: Educational mobility and social capital in germany, Social Indicators Research 142 (2) (2019) 855-885.

9. F. Stephany, Who are your joneses? socio-specific income inequality and trust, Social indicators research 134 (3) (2017) 877-898.

10. F. Stephany, F. Braesemann, et al., Bonds and bridges, and between: An empirical analysis of group-based trust, Tech. rep. (2017).

11. F. Stephany, F. Braesemann, An exploration of wikipedia data as a measure of regional knowledge distribution, in: International Conference on Social Informatics, Springer, 2017, pp. 31-40.

12. F. Björklund, E-government and moral citizenship: The case of estonia, Citizenship studies 20 (6-7) (2016) 914-931.

13. K. Schmidheiny, U. Basel, Panel data: fixed and random effects, Short Guides to Microeconometrics (2011) 2-7. 